\title{
Fractures and musculoskeletal ailments in persons $20+$ years after a traumatic spinal cord injury in Norway
}

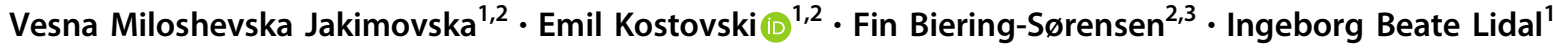

Received: 20 February 2018 / Revised: 8 June 2018 / Accepted: 17 June 2018

(c) International Spinal Cord Society 2018

\begin{abstract}
Study design Cross-sectional study.

Objectives To gain insights into fracture rate and musculoskeletal ailments among Norwegians with a spinal cord injury (SCI) acquired more than 20 years ago.

Settings Sunnaas Hospital, Nesoddtangen, Norway

Methods 165 persons with SCI were interviewed in 2004-2005 by questionnaires and clinical examination. Descriptive statistics and a logistic regression analysis were performed to identify variables associated with bone fractures and musculoskeletal ailments.

Results Around half of the participants experienced a fracture after injury and excessive use of alcohol increased the odds (OR 0.09; CI 0.01-0.74) of suffering a post-injury fracture $(p=0.03)$. Sixty percent experienced shoulder ailments after the SCI and the use of orthosis to the knee and hip increased the odds (OR 4.4; CI 1.4-13) of experiencing shoulder ailment ( $p$ $=0.01$ ).

Conclusion Around half of the 165 participants reported to have suffered a fracture and over 100 to experience musculoskeletal ailment 20 years after injury. We suggest that prevention strategies and symptom management must be embedded in follow-up visits after SCI.
\end{abstract}

\section{Introduction}

After a traumatic spinal cord injury (SCI) the muscle mass below the injury level rapidly atrophies and loses strength [1]. Paralyzed muscles and diminished vertical load on bones below injury level result in extensive bone loss, and bone fractures due to osteopenia/osteoporosis is not uncommon in the chronic stage [2-6]. Complications after fracture-related hospital stays are more common [7], length of stay is longer, and hospitalized persons with

Electronic supplementary material The online version of this article (https://doi.org/10.1038/s41394-018-0102-7) contains supplementary material, which is available to authorized users.

Vesna Miloshevska Jakimovska

v.m.jakimovska@studmed.uio.no

1 Sunnaas Rehabilitation Hospital, Nesoddtangen, Norway

2 Faculty of Medicine, University of Oslo, Oslo, Norway

3 Clinic for Spinal Cord Injuries, Rigshospitalet, University of Copenhagen, Copenhagen, Denmark
SCI and fractures are more often discharged to other institutions $[8,9]$. In a rehabilitation context, a major challenge is finding ways to improve function after a traumatic SCI and to reduce the risk of complications. One strategy may be to "compensate" by increasing the amount of exercise of the able-bodied part of the body, which may over time increase the risk of overuse-related ailments [10]. The use of assistive aids may relieve and improve function, but can also be among the causes of aches and overuse symptoms. Fracture rate and musculoskeletal ailments in Norwegians living with a SCI for most of their adult life has not previously been described. Such knowledge is useful when planning SCI follow-up visits. In the 60's, 70's, and early 80's in Norway, the vast majority of persons with SCI was rehabilitated at Sunnaas Rehabilitation Hospital only. Hence, choosing persons living with a SCI for more than 20 years will make our results more generalizable for the whole of Norway. Thus, our aim with this paper is to describe fracture rate, and musculoskeletal ailments reported by persons living most of their adult life $(20+y)$ with an SCI. 


\section{Material and methods}

\section{Inclusion, setting, and data collection procedures}

We included persons with traumatic SCI, injured more than 20 years ago and admitted for initial rehabilitation at Sunnaas Rehabilitation Hospital (SunRH) between 1961 and 1982. The data collection, which took place in 2004/5, has been previously described [11]. In short, participants answered a questionnaire in face-to-face interview. The Regional Ethics Committee in Oslo, Norway, approved the study.

\section{Measures}

Demographic information included gender, age at the time of the study, and time since injury. Injury-related data presented are injury cause and injury severity according to the American Spinal Injury Association (ASIA) Impairment Scale (AIS) [12-14]. Questionnaires (A) on fractures, musculoskeletal ailments (Appendix A), aid, and assistance (Appendix B) was developed for this study and (B) regarding their experiences during the period after the initial rehabilitation until the time of the interview. Our questionnaire about fractures consisted of three questions: Have you experienced bone fracture(s) after the SCI and up to the current date? If you suffered bone fracture(s), can you please specify the location? If you suffered bone fracture(s), can you please indicate the trauma mechanism (spontaneous, fragile, or traumatic). We define spontaneous fractures as when the patient could not recall the trauma, fragile fractures happened without sufficient force, and traumatic fractures due to a low or high energy trauma. Muscular overuserelated symptoms (Appendix A) were included to cover ailments not specifically inquired about, including neck ailments. The participants were divided into the following neurological subgroups: C4 AIS A, B, or C (i); C5-8 AIS A, $\mathrm{B}$, or C (ii); Th1-S5 AIS A, B, or C (iii); and AIS D and E at any injury level (iv), based on recommendations from Biering-Sørensen et al. [12]. Smoking habits were noted as "non-smokers" or "smokers or previously smokers". The participants reported alcohol intake as "excessive use" or "normal/no use". We also present a fracture group, a shoulder and elbow ailment group, and a hand pain group, i.e., those who had experienced one or more bone fracture(s) or ailment/pain after the SCI, and a non-fracture and nonailment/pain group. The latter group did not recall having experienced a fracture or ailments/pain after the injury.

\section{Statistical analyses}

The statistical analyses were performed with SPSS version 24 (Chicago, IL). Descriptive statistics included proportions, ranges, means, and standard deviations (SD), together with simple tests including Fisher's exact and $\chi^{2}$ tests to compare categorical variables, and $t$-tests and Mann-Whitney $U$ tests to compare continuous variables. We performed a binary logistic regression analysis with fracture group versus non-fracture group and shoulder ailments group versus non-shoulder ailments group as the dependent variable, to study factors that might be associated with having experienced one or more fractures or shoulder ailments during the years after initial rehabilitation. Age (continuous variable (cont.)), gender (categorical variable (cat.)), ASIA motor score ((International Standards for Neurological Classification of Spinal Cord Injury (ISNCSCI))(cont.)), BMI (cont.), and smoking habits (cat.) were included in the logistic regression using the Enter method. Variables, with a $p$-value $\leq 0.1$ were included using the backward likelihood ratio (LR) method. Values are reported as odds ratios (ORs) with intercept $(B)$ with standard error and $95 \%$ confidence intervals (CIs). We chose a significance level of $p<0.05$.

\section{Results}

\section{Characteristics of the study participants}

A total of 163 persons with SCI answered the questionnaires about fractures and musculoskeletal ailments and 165 answered the use of aid(s) and assistance. Participant's characteristics are described in Table 1. See previous publication for further information on characteristics [15].

\section{Fractures}

Fifty-two percent of the participants had experienced a fracture after the injury, the fracture incidence varied (not significantly) from $46 \%$ (group iv) to $51 \%$ (group iii) and $57 \%$ group $(i i+i)$. There was only one patient reporting to have experienced a fragility fracture, and none with spontaneous fractures. Table 2 presents details of the anatomical location of the fractures. The most frequently fractured bones were tibia/fibula $(n=21)$, followed by the femur ( $n$ $=19)$, and the bones in the foot or toes $(n=7)$. Table $3 \mathrm{a}$ shows the results of the logistic regression, i.e., the association between different variables on fracture group and non-fracture group. Our model explained $9 \%$ of the relationship between the two groups. The logistic regression analysis revealed that excess use of alcohol increased the risk of being in the fracture group $(p=0.02)$.

\section{Musculoskeletal ailments}

Appendix A presents the participants' responses to the musculoskeletal ailments questionnaire. Shoulder and back 
Table 1 Characteristics of participants

\begin{tabular}{ll}
\hline & $n=165$ \\
\hline Gender $(n)$ & \\
Male & 135 \\
Female & 30 \\
Mean time since injury (SD)(y) & $27(4)$ \\
Range & $21-37$ \\
Mean age at interview (SD) (y) & $51(10)$ \\
Range & $24-81$ \\
Level of injury $(n)$ & \\
Tetraplegia & 60 \\
Paraplegia & 105 \\
AIS classification $(n)$ & \\
A & 113 \\
B & 13 \\
C & 11 \\
D & 19 \\
E & 5 \\
Missing & \\
AIS classification $(n)$ & 4 \\
C4 AIS A, B and C & \\
C5-C8 AIS A, B, and C & $23.3(5)$ \\
Th1 to S1 AIS A, B, and C & $(13-37)$ \\
Any level AIS D and E & $(n=108)$ \\
BMI (kilo/meter $\times$ meter) & 3 \\
Mean (SD); Range; $(n)$ & 48 \\
& \\
\hline
\end{tabular}

Demographic-related and injury-related characteristics of all participants. Values are given in absolute numbers, percentages, mean (SD), and/or range within the group

$S D$ standard deviation, AIS ASIA impairment Scale, ASIA American Spinal Injury Association

ailments were reported by $61 \%$ and $46 \%$, respectively, of all participants. Muscular overuse-related symptoms were reported by $44 \%$ of the participants. Elbow ailments and hand pain were reported by around $30 \%$. Shoulder ailments were present in $65 \%$ of the participants in group $(i+i i)$ and (iii), whereas in contrast to $45 \%$ in group (iv) $(p=0.04)$. Back ailments were present in $65 \%$ of the participants in group (iv), $47 \%$ in group (iii), and $35 \%$ in group ( $i+$ ii) $(p$ $=0.04)$. Muscular overuse-related symptoms were present in $41 \%$ in group (i + ii), $53 \%$ in group (iii), and $23 \%$ in group (iv) $(p=0.02)$. Elbow ailments were present in $23 \%$ (group (iv)), 33\%, and 36\% (group (i+ii)) and (iii) $(p=$ 0.46)) of the participants, with hand pain occurring in a similar fashion. Physiotherapy or no treatment was the most common management for musculoskeletal ailments, compared to medicine, surgery, rest, or training.
Table 2 Fracture anatomical site after SCI

\begin{tabular}{|c|c|c|c|c|}
\hline $\begin{array}{l}\text { Anatomical } \\
\text { Site }\end{array}$ & $\begin{array}{l}\text { Tetraplegic } \\
\text { AIS A,B,C } \\
(n=45)\end{array}$ & $\begin{array}{l}\text { Tetraplegic } \\
\text { AIS D,E }(n \\
=13)\end{array}$ & $\begin{array}{l}\text { Paraplegic } \\
\text { AIS A,B,C } \\
(n=90)\end{array}$ & $\begin{array}{l}\text { Paraplegic } \\
\text { AIS D,E }(n \\
=15)\end{array}$ \\
\hline Total & 25 & 4 & 43 & 7 \\
\hline Upper arm & None & None & None & None \\
\hline Forearm & 1 & None & 1 & 2 \\
\hline Fingers & None & None & None & None \\
\hline Hip & 1 & 1 & 3 & None \\
\hline Femur & 8 & None & 10 & 1 \\
\hline Knee & 1 & None & 2 & None \\
\hline Tibia/fibula & 5 & 1 & 14 & 1 \\
\hline Ankle & 2 & None & 2 & None \\
\hline Foot & None & None & 2 & None \\
\hline Toes & 2 & 1 & 1 & 1 \\
\hline Other & 3 & None & 3 & 2 \\
\hline $\begin{array}{l}\text { Femur }+ \\
\text { another } \\
\text { bone }\end{array}$ & 2 & 1 & 5 & None \\
\hline
\end{tabular}

Values are frequencies

AIS ASIA Impairment Scale, ASIA American Spinal Injury Association

Table 3a Fractures logistic regression

\begin{tabular}{lllllll}
\hline & $B$ & S.E. & Sig. & OR & \multicolumn{2}{l}{$\begin{array}{l}\text { 95\% C.I.for } \\
\text { OR }\end{array}$} \\
\cline { 5 - 7 } & & & & & & \\
\cline { 5 - 7 } & & & & & Lower & Upper \\
\hline $\begin{array}{l}\text { Gender } \\
\text { Age }\end{array}$ & 0.531 & 0.527 & 0.314 & 1.700 & 0.605 & 4.781 \\
$\begin{array}{l}\text { Do you smoke or } \\
\text { have smoked (Y/N) }\end{array}$ & -0.037 & 0.404 & 0.926 & 0.963 & 0.436 & 2.128 \\
$\begin{array}{l}\text { Body mass index, } \\
\text { kilo/meter } \times \text { meter }\end{array}$ & 0.015 & 0.023 & 0.519 & 1.015 & 0.970 & 1.062 \\
$\begin{array}{l}\text { Sum, motor score } \\
\text { (AIS) }\end{array}$ & 0.010 & 0.009 & 0.255 & 1.010 & 0.993 & 1.028 \\
$\begin{array}{l}\text { Do you use much } \\
\text { alcohol (Y/N) }\end{array}$ & -2.425 & 1.082 & 0.025 & 0.088 & 0.011 & 0.738 \\
\hline
\end{tabular}

Variables included in a multivariate regression model. * $p$-value $<0.05$ Model Summary: Cox \& Snell $R^{2}: 0.09$

AIS ASIA impairment scale, ASIA American Spinal Injury Association Impairment Scale, $B$ intercept, $O R$ odds ratio

$* p$-value $<0.05$

\section{Increased use of leg braces is associated with shoulder ailments}

In Appendix B, we present our participants' use of a range of aids and needs of assistance. We chose to explore shoulder ailment and the use of aids by logistic regression and not to explore back ailments, as we did not characterize back pain further (nociceptor and neuropathic associated), 


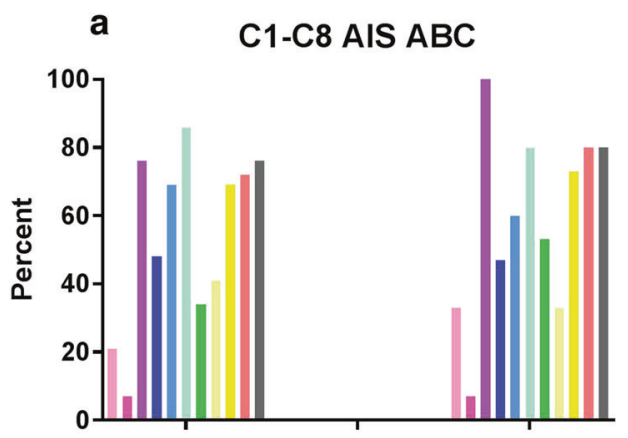

b TH1-L5 AIS ABC
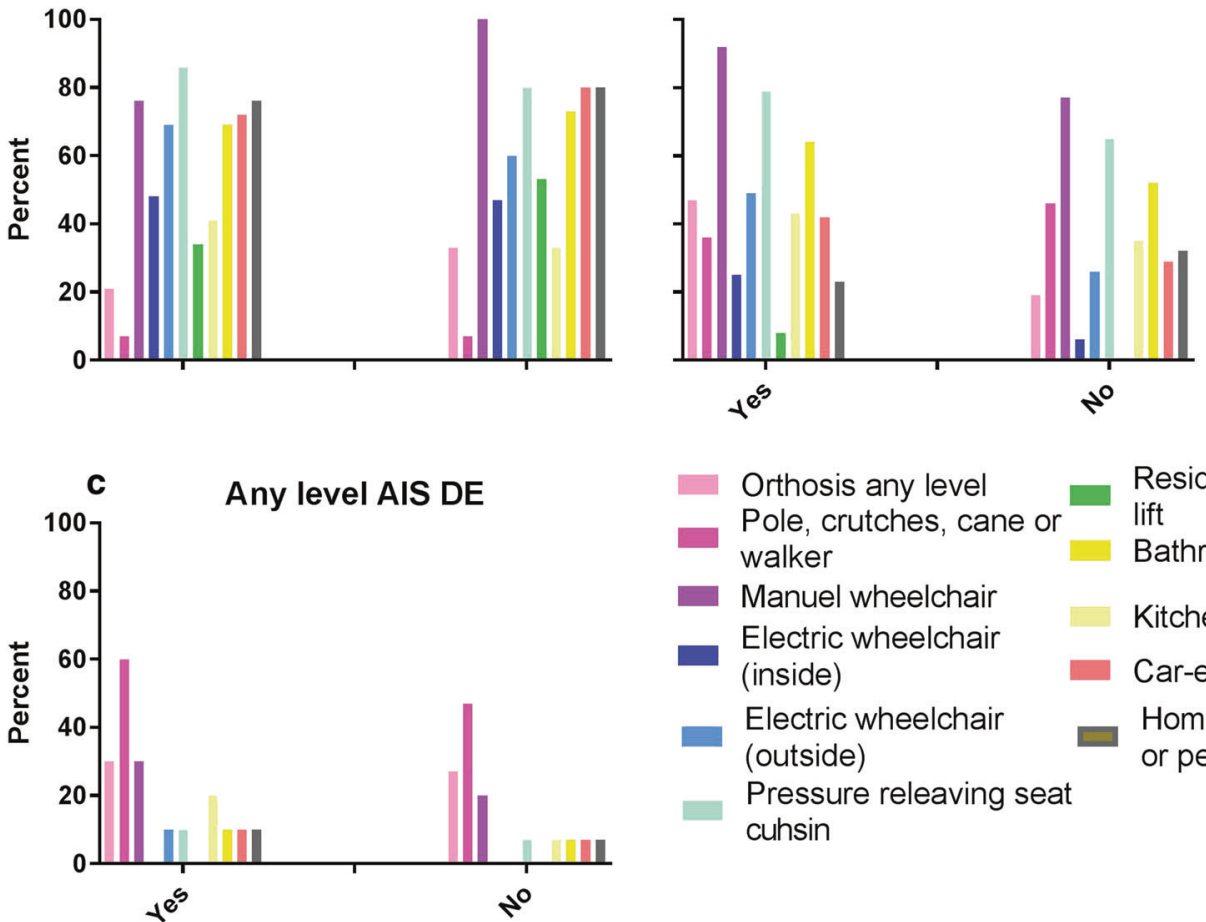

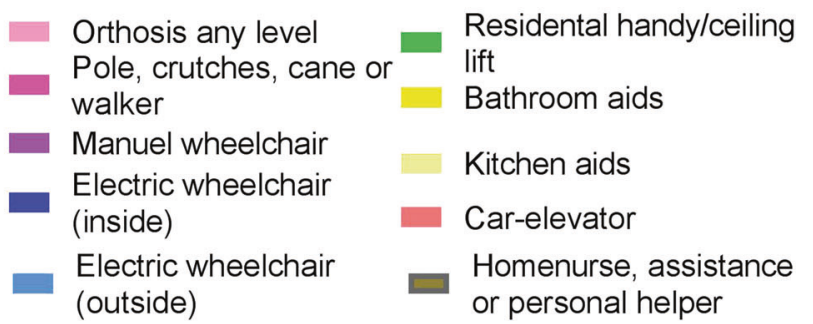

Pressure releaving seat

cuhsin

Fig. 1 Values are expressed as participants' use of aids or assistance in percent (\%) within each group (a) (i + ii), (b) (ii), and (c) (iv) and having or not having shoulder ailments

and furthermore hand pain and elbow ailments correlated with shoulder ailments. In Fig. 1 we present the use of aids and assistance divided in groups defined as "having (Yes)" or "not having (No)" shoulder ailments in group (i + ii), (iii) and (iv). In order to give an easy and immediately/quickly accessible impression of the use of aids and assistance, we choose to present a selected number of aids and pooled other aids and assistance into groups of similar "function", for example, the "orthosis any level" group includes orthosis to the hip, knee and lower extremities as well as orthopedic shoes. There was no obvious visual difference between the "yes" and "no" group, regardless of severity of injury (Fig. 1). Our logistic regression model (Table 3b) explained $15 \%$ of the relationship between the two groups of shoulder ailments (Yes) and non-shoulder ailments (No) among all participants. The logistic regression analysis revealed that the use of orthosis to the knee or hip (long braces) increased the risk of belonging to the shoulder ailments group $(p=0.01)$.

\section{Discussion}

We have described musculoskeletal ailments in 165 people living with their SCI-disability for more than 20 years in
Table 3b Shoulder ailments logistic regression

\begin{tabular}{|c|c|c|c|c|c|c|}
\hline & \multirow[t]{2}{*}{$B$} & \multirow[t]{2}{*}{ S.E. } & \multirow[t]{2}{*}{ Sig. } & \multirow[t]{2}{*}{ OR } & \multicolumn{2}{|c|}{$\begin{array}{l}\text { 95\% C.I.for } \\
\text { OR }\end{array}$} \\
\hline & & & & & Lower & Upper \\
\hline Gender & 0.19 & 0.56 & 0.74 & 1.21 & 0.40 & 3.61 \\
\hline Age & 0.00 & 0.02 & 0.87 & 1.00 & 0.96 & 1.05 \\
\hline $\begin{array}{l}\text { Do you smoke or have } \\
\text { smoked }(\mathrm{Y} / \mathrm{N})\end{array}$ & 0.63 & 0.43 & 0.15 & 1.88 & 0.80 & 4.40 \\
\hline $\begin{array}{l}\text { Body mass index, kilo/ } \\
\text { meter } \times \text { meter }\end{array}$ & 0.01 & 0.03 & 0.72 & 1.01 & 0.96 & 1.06 \\
\hline Sum, motor score (AIS) & 0.01 & 0.01 & 0.27 & 1.01 & 0.99 & 1.03 \\
\hline Orthosis to knee or hip & 1.48 & 0.57 & 0.01 & 4.39 & 1.44 & 13.41 \\
\hline $\begin{array}{l}\text { Electric wheelchair for } \\
\text { outside use }\end{array}$ & -0.74 & 0.49 & 0.13 & 0.48 & 0.18 & 1.24 \\
\hline
\end{tabular}

Variables included in a multivariate regression model

Model Summary: Cox \& Snell $R^{2}: 0.15$

AIS ASIA impairment scale, ASIA American Spinal Injury Association Impairment Scale, $B$ intercept, $O R$ odds ratio

$* p$-value $<0.05$

Norway. Our main findings are that half of the study sample had experienced a bone fracture, regardless of severity of injury, and excessive use of alcohol increased the odds of being a fracture case. Shoulder and back ailments were the most commonly experienced musculoskeletal secondary 
complications during the years post injury, and the use of orthosis to the knee or hip increased the odds of being a shoulder ailment case.

In our study, around 50\% reported to have had a fracture during the post-injury years, regardless of severity of injury. We emphasize that our reports of fractures reflect a time period of more than 20 years after injury (mean 27 years). Our incidence rate is high, but it is to be taken into consideration that Scandinavia has one of the highest incidence rates of hip fractures in the world [16]. A recent review estimates that up to $50 \%$ of persons with SCI will experience a fracture during their lifetime [3]. Our study confirms the results of a study from Sweden and Italy [17]. The Swedish-Italian study did not include persons with incomplete SCI, as we did, as our study found nearly half of the AIS D participants to have suffered a fracture. High fracture rates in AIS D at 20 years post injury may suggest cumulative impact of decreased mobility and age-related bone loss. This may imply that preservation of bone health is as important for persons with incomplete as complete $\mathrm{SCI}$, and/or they may be more active due to less severe paralyses and consequently at higher risk of fracture. In a review by Dionyssotis [18], studies report percentage of fractures to be from 2 to $40 \% 15$ years after injury. In a review by Edwards and Schnitzer, the authors state that the rate of fractures among SCI persons are comparable to the rate of non-vertebral fractures observed in osteoporotic menopausal women [3]. Other studies report prevalence of yearly fracture rates ranging from 1 to $4 \%$; Zehnder et al. observed a fracture rate of $4.6 \%$ a year among persons living with their injury for more than 20 years, whereas Mckinley et al. report a prevalence of around 2\% 20 years after injury [4, 19-21]. The most common location of the fracture was similar to findings shown by others, i.e., around the knee $[2,3]$. We found that excessive use of alcohol increased the odds ratio of belonging to the fracture group, which is also reported by Morse et al. [9]. Relatively few persons reported excessive alcohol usage $(n=12)$, thus a broad CI, but we still believe our findings are valid and generalizable as $83 \%(n=10)$ of those using excessive alcohol were in the fracture group.

Shoulder ailments were the most frequent musculoskeletal problem reported in participants with a functional complete SCI (AIS A, B, C), and back ailments in participants with a functional incomplete SCI (AIS D and E). Our study reports higher overall frequency of shoulder ailments (61\%) compared to a Swiss study reporting 36\% [22], but our participants had lived longer with their SCI. However, a review by Paolucci et al. reported shoulder pain from 37 to $84 \%$ and elbow and hand pain from 32 to $48 \%$ in persons with SCI [23], similar to our results. Overall, back pain in our study was in accordance with the $49 \%$ found in a review by Michailidou et al. [24]. Our findings of increased odds of experiencing shoulder ailments when using orthosis to the knee or hip could indicate that the use of orthosis adds an additional load to the shoulders when walking and thus the development of ailments, which also has been reported previously [25]. Hand pain is common $(n=45)$, whereas contractures, tendinitis, arthrosis, and reflex dystrophy were rarely reported (Appendix A) in our study.

Physiotherapy or non-treatment was the overall preferred management, followed by medication. Shoulder ailments are thought to influence everyday living; however, it seems to be left untreated in $30 \%$ of the participants in this study. Our questionnaire did not include the participants' own grading of the problem or his/her opinion on the need for treatment. Thus, the severity might also be minor, and therefore not handled. We speculate that one of the reasons for not treating conditions of the upper extremity could be the patient's concern of losing function, at least when it comes to surgical management.

\section{Study limitations}

Due to the design of the study, we found it difficult to divide fractures into low force impact (traumatic), spontaneous, and fragile fractures; we therefore chose to combine them in one group: traumatic. Many of those with "muscular overuse related symptoms" (Appendix A) are within/ overlap with the numbers presented as shoulder, back, and elbow ailments, since the questionnaire did not distinguish between these in this regard. In a previous paper, the representativeness of the study group has been commented on [26]. It was indicated that individuals with more severe conditions may be less likely to participate in a population survey and our retrospective questions might have introduced risk of recall bias. Still, we believe that the results of this study are of importance and valid. The article describes data not previously described, with 165 Norwegians with SCI including incomplete injuries, a mean time from injury of 27 years, all face-to-face interviewed by one person. It is of utmost importance to publish fracture data from persons with SCI, especially due to the high complication rate and increased mortality rate [7] after fractures, thereby focusing more on preventive measures, also among persons with incomplete SCI.

\section{Conclusions}

Around half of the 165 persons with SCI had experienced fractures and over 100 had experienced musculoskeletal ailments $20+$ years after the injury. Fractures and musculoskeletal ailments are common among persons with chronic SCI. Excessive use of alcohol increased the odds of suffering a fracture and the use of orthosis to knee or hip of 
experiencing shoulder ailments 20 years after injury. We suggest that both prevention strategies and symptom management should be embedded in each follow-up visit after SCI.

Acknowledgements We want to thank the study participants, the Norwegian Association of the Disabled, Norwegian Association for Spinal Injuries, Norwegian Foundation for Health and Rehabilitation (EXTRA), the Sunnaas Rehabilitation Hospital, Eastern Norway Health Authority (Helse Øst), and the QUOTA program for contributing financial support to the project.

\section{Compliance with ethical standards}

Statements of ethics We certify that all applicable institutional and governmental regulations concerning the ethical use of human volunteers were followed during the course of this research.

Conflict of interest The authors declare that they have no conflict of interest.

\section{References}

1. Castro MJ, Apple DF Jr, Hillegass EA, Dudley GA. Influence of complete spinal cord injury on skeletal muscle cross-sectional area within the first 6 months of injury. Eur J Appl Physiol Occup Physiol. 1999;80:373-8.

2. Jiang SD, Jiang LS, Dai LY. Mechanisms of osteoporosis in spinal cord injury. Clin Endocrinol. 2006;65:555-65.

3. Edwards WB, Schnitzer TJ. Bone imaging and fracture risk after spinal cord injury. Curr Osteoporos Rep. 2015;13:310-7.

4. Troy KL, Morse LR. Measurement of bone: diagnosis of SCIinduced osteoporosis and fracture risk prediction. Top Spinal Cord Inj Rehabil. 2015;21:267-74.

5. Cervinka T, Lynch CL, Giangregorio L, Adachi JD, Papaioannou A, Thabane L, et al. Agreement between fragility fracture risk assessment algorithms as applied to adults with chronic spinal cord injury. Spinal Cord. 2017;55:985-93.

6. Cirnigliaro CM, Myslinski MJ, La Fountaine MF, Kirshblum SC, Forrest GF, Bauman WA. Bone loss at the distal femur and proximal tibia in persons with spinal cord injury: imaging approaches, risk of fracture, and potential treatment options. Osteoporos Int. 2017;28:747-65.

7. Carbone LD, Chin AS, Burns SP, Svircev JN, Hoenig H, Heggeness $\mathrm{M}$, et al. Mortality after lower extremity fractures in men with spinal cord injury. J Bone Mineral Res. 2014;29:432-9.

8. Bauman WA, Cardozo CP. Osteoporosis in individuals with spinal cord injury. PM R. 2015;7:188-201.

9. Morse LR, Battaglino RA, Stolzmann KL, Hallett LD, Waddimba A, Gagnon D, et al. Osteoporotic fractures and hospitalization risk in chronic spinal cord injury. Osteoporos Int. 2009;20:385-92.

10. Lidal IB, Veenstra M, Hjeltnes N, Biering-Sorensen F. Healthrelated quality of life in persons with long-standing spinal cord injury. Spinal Cord. 2008;46:710-5.
11. Jakimovska VM, Kostovski E, Biering-Sorensen F, Lidal IB. Psychological distress and user experiences with health care provision in persons living with spinal cord injury for more than 20 years. Spinal Cord. 2017;55:864-9.

12. Biering-Sorensen F, DeVivo MJ, Charlifue S, Chen Y, New PW, Noonan V, et al. International Spinal Cord Injury Core Data Set (version 2.0)-including standardization of reporting. Spinal Cord. 2017;55:759-64.

13. Kirshblum SC, Burns SP, Biering-Sorensen F, Donovan W, Graves DE, Jha A, et al. International standards for neurological classification of spinal cord injury (revised 2011). J Spinal Cord Med. 2011;34:535-46.

14. DeVivo MJ, Biering-Sorensen F, New P, Chen Y. Standardization of data analysis and reporting of results from the International Spinal Cord Injury Core Data Set. Spinal Cord. 2011;49:596-9.

15. Lidal VMJEKFB-SIB. Musculoskeletal issues, mobility aids and assistance in persons $20+$ years after a traumatic spinal cord injury in Norway. 2017.

16. Pripp AH, Dahl OE. The population attributable risk of nutrition and lifestyle on hip fractures. Hip Int. 2015;25:277-81.

17. Werhagen L, Aito S, Tucci L, Strayer J, Hultling C. 25 years or more after spinal cord injury: clinical conditions of individuals in the Florence and Stockholm areas. Spinal Cord. 2012;50:243-6.

18. Dionyssiotis Y. Spinal cord injury-related bone impairment and fractures: an update on epidemiology and physiopathological mechanisms. J Musculoskelet Neuron Interact. 2011;11:257-65.

19. McKinley WO, Jackson AB, Cardenas DD, DeVivo MJ. Longterm medical complications after traumatic spinal cord injury: a regional model systems analysis. Arch Phys Med Rehabil. 1999;80:1402-10.

20. Zehnder Y, Luthi M, Michel D, Knecht H, Perrelet R, Neto I, et al. Long-term changes in bone metabolism, bone mineral density, quantitative ultrasound parameters, and fracture incidence after spinal cord injury: a cross-sectional observational study in 100 paraplegic men. Osteoporos Int. 2004;15:180-9.

21. Vestergaard P, Krogh K, Rejnmark L, Mosekilde L. Fracture rates and risk factors for fractures in patients with spinal cord injury. Spinal Cord. 1998;36:790-6.

22. Bossuyt FM, Arnet U, Brinkhof MWG, Eriks-Hoogland I, Lay V, Muller R, et al. Shoulder pain in the Swiss spinal cord injury community: prevalence and associated factors. Disabil Rehabil. 2018;40:798-805.

23. Paolucci S, Martinuzzi A, Scivoletto G, Smania N, Solaro C, Aprile I, et al. Assessing and treating pain associated with stroke, multiple sclerosis, cerebral palsy, spinal cord injury and spasticity. Evidence and recommendations from the Italian Consensus Conference on Pain in Neurorehabilitation. Eur J Phys Rehabil Med. 2016;52:827-40.

24. Michailidou C, Marston L, De Souza LH, Sutherland I. A systematic review of the prevalence of musculoskeletal pain, back and low back pain in people with spinal cord injury. Disabil Rehabil. 2014;36:705-15.

25. Hardin EC, Kobetic R, Triolo RJ. Ambulation and spinal cord injury. Phys Med Rehabil Clin N Am. 2013;24:355-70.

26. Lidal IB, Jensen AE, Larsen TW, Stanghelle JK. Fatigue in persons who have lived with spinal cord injury for $>20$ years. Spinal Cord. 2013;51:103-8. 